\title{
Transthoracic echocardiographic reference values of the aortic root: results from the Hamburg City Health Study
}

\author{
Jan-Per Wenzel ${ }^{1,4}$ (I) Elina Petersen ${ }^{4}$. Julius Nikorowitsch ${ }^{1}$. Juliana Senftinger ${ }^{1}$. Christoph Sinning ${ }^{1,2}$. \\ Matthias Theissen $^{3} \cdot$ Johannes Petersen $^{2,3} \cdot$ Hermann Reichenspurner $^{3} \cdot$ Evaldas Girdauskas $^{2,3}$
}

Received: 27 May 2021 / Accepted: 16 July 2021 / Published online: 29 July 2021

(C) The Author(s) 2021

\begin{abstract}
Here we generate up-to-date reference values of transthoracic echocardiographic aortic root dimensions matched by sex, age, and body surface area (BSA) derived from the population-based Hamburg City Health Study (HCHS) cohort. In 1687 healthy subjects (mean age 57.1 \pm 7.7, 681 male and 1006 female), derived from the first prospectively-recruited 10,000 HCHS participants, dimensions of the aortic root were measured in systole and diastole using state-of-the-art 2-dimensional transthoracic echocardiography. Diameters were assessed at four levels: aortic annulus, Sinus of Valsalva, sinotubular junction, and ascending aorta. Female sex was associated with significantly smaller absolute aortic root dimensions, while indexing for BSA resulted in a reverse effect at all levels. There was a strong age dependency of all aortic root diameters as well as aortic annulus/sinotubular junction ratio for both sexes. Multivariate analysis revealed age, sex, weight, height, and BSA to be significant determinants of aortic root size. Finally, formulas were generated for the calculation of individual aortic root reference values considering age, sex, weight, and height. We provide population-based reference values of aortic root diameters based on a standardized transthoracic echocardiographic protocol of the population-based HCHS which may support the diagnosis, monitoring, and treatment of aortic root disease.
\end{abstract}

Keywords Aortic root · Echocardiography $\cdot$ Reference values $\cdot$ HCHS $\cdot$ Hamburg City Health Study $\cdot$ Thoracic aorta

\begin{tabular}{llll}
\multicolumn{2}{l}{ Abbreviations } & EACVI & $\begin{array}{l}\text { European Association of Cardiovascular } \\
\text { Asc }\end{array}$ \\
Ascending & & Imaging \\
Ao & Aorta/aortic & ED & End-diastolic/diastole \\
ASE & American Society of Echocardiography & ESC & European Society of Cardiology \\
BMI & Body mass index & GFR & Glomerular filtration rate \\
BSA & Body surface area & HCHS & Hamburg City Health Study \\
& & hsCRP & High sensitivity C-reactive protein
\end{tabular}

Jan-Per Wenzel

ja.wenzel@uke.de

Elina Petersen

e.petersen@uke.de

Julius Nikorowitsch

j.nikorowitsch@uke.de

Juliana Senftinger

j.senftinger@uke.de

Christoph Sinning

c.sinning@uke.de

Matthias Theissen

matthias.theissen@stud.uke.uni-hamburg.de

Johannes Petersen

joh.petersen@uke.de
Hermann Reichenspurner

reichenspurner@uke.de

Evaldas Girdauskas

e.girdauskas@uke.de

1 Department of Cardiology, University Heart and Vascular Centre Hamburg, Hamburg, Germany

2 German Centre for Cardiovascular Research (DZHK), Partner Site Hamburg/Kiel/Luebeck, Hamburg, Germany

3 Department of Cardiovascular Surgery, University Heart Centre Hamburg, Hamburg, Germany

4 Epidemiological Study Centre, Hamburg, Germany 


$\begin{array}{ll}\text { IMT } & \text { Intima media thickness } \\ \text { IVST } & \begin{array}{l}\text { Interventricular septum thickness } \\ \text { Left atrial systolic volume indexed to body } \\ \text { LAVI }\end{array} \\ \text { surface area } \\ \text { LVEDD } & \text { Left ventricular end-diastolic diameter } \\ \text { LVEDV } & \text { Left ventricular end-diastolic volume } \\ \text { LVEF } & \text { Left ventricular ejection fraction } \\ \text { MS } & \text { Mid-systolic/systole } \\ \text { NT-proBNP } & \text { N-terminal pro-B-type natriuretic peptide } \\ \text { NYHA } & \text { New York Heart Association } \\ \text { STJ } & \text { Sinotubular junction } \\ \text { TAPSE } & \text { Tricuspid annular peak systolic excursion }\end{array}$

\section{Introduction}

Aortic root dilatation is a common and multifactorial condition influenced by genetics, hemodynamic-rheological factors, and comorbidities [1]. If significant and progressive, it may lead to aortic valve regurgitation (AR) [2, 3]. Furthermore, an increased aortic root diameter has been shown to be an independent predictor of acute aortic syndrome which is associated with an increased morbidity and mortality [3-5]. Transthoracic echocardiography (TTE) is the most commonly used imaging modality to evaluate the aortic root in the daily clinical practice. This is predominantly due to its wide availability, non-invasiveness, ease of use, and reproducibility. Echocardiographic screening, grading, and surveillance of aortic root aneurysms has a major impact on the patient care. However, the assessment of the aortic root is highly dependent on the acoustic window, proper alignment, the exact location of measurements as well as the availability of validated reference values. Indeed, most of the previously published aortic root reference studies are potentially biased by limited sample sizes, heterogenous measuring techniques and selective study populations [6-9].

The Hamburg City Health Study (HCHS, www.hchs. hamburg) is a single-centre, prospective, long-term, population-based cohort study which targets the interaction of socioeconomic risk factors, modern imaging techniques, physiological measurements, and clinical variables [10]. HCHS will finally include a random sample of approximately 45,000 inhabitants from the general population of Hamburg, Germany aged 45 to 74 years. Based on the inclusion of a sample of the first 10,000 HCHS study participants, the present study aims to define 2-dimensional TTE aortic root reference values derived from a standardized echocardiographic protocol adjusted for age, sex, height, weight, and BSA.

\section{Methods}

\section{Study population}

Our study population included a sample of the first 10,000 HCHS participants who received transthoracic ultrasound evaluation. Of 10,000 study individuals, 7644 received TTE with evaluation of the aortic root. Of those 7644 individuals, we excluded 5957 individuals due to arterial hypertension (blood pressure at rest $>140 / 90 \mathrm{mmHg}$ ), medication (betablockers, ace-inhibitors, angiotensin II receptor blockers, aldosterone antagonists, statins, diuretics), coronary artery disease, peripheral artery disease, atrial fibrillation, diabetes mellitus, rheumatic disease, obesity $\left(\mathrm{BMI}>35 \mathrm{~kg} / \mathrm{m}^{2}\right)$, moderate/severe aortic regurgitation, any aortic stenosis, relevant mitral-/tricuspid valve disease, bicuspid aortic valve, left ventricular ejection fraction (LVEF) below 50\% or insufficient image quality to perform standardised measurements. Hence, 1,687 individuals served as our study population for the current analysis (Fig. 1).

All measurements were conducted between 2016 and 2018 during a one-day baseline visit at the HCHS Epidemiological Study Centre Hamburg-Eppendorf, Germany, according to the published study protocol [10]. The research protocol was approved by the HCHS steering board and the local ethics committee (PV5131, Medical Association Hamburg). All participants gave written informed consent.

\section{TTE image acquisition and analysis}

TTE examinations were systematically performed on dedicated ultrasound machines (Siemens Acuson SC2000 Prime, Siemens Healthineers, Erlangen, Germany) using grey-scale second-harmonic imaging technique at the HCHS Epidemiological Study Centre Hamburg-Eppendorf, Germany. The TTE examination followed a strictly standardized protocol which included all the established standard echocardiographic views as well as Doppler velocimetry and 3D visualization. All loops were recorded in native DICOM format and included three ECG-triggered heartbeats. For the assessment of the aortic root, the transthoracic parasternal long axis view of the left ventricle (LV) with focused zoom of the left ventricular outflow tract (LVOT) and the aortic root was recorded at breath hold in consent with the current ASE/EACVI guidelines [11]. To improve image quality, manual adjustments of image depth, sector width, frequency, and gain intensity were applied. For qualitative and quantitative image analysis standard operating procedures (SOP) were defined in agreement 
Fig. 1 Study PRISMA. From a total of 7644 subjects with available TTE examination and aortic root measurements, 5106 were excluded due to comorbidities, 601 subjects were excluded due to medication use, and 250 due to pathologic echocardiographic findings. Consequently, 1687 subjects were considered applicable for the measurement and calculation of aortic root reference values matched by age, sex, and body surface area. $L V E F$ left ventricular ejection fraction

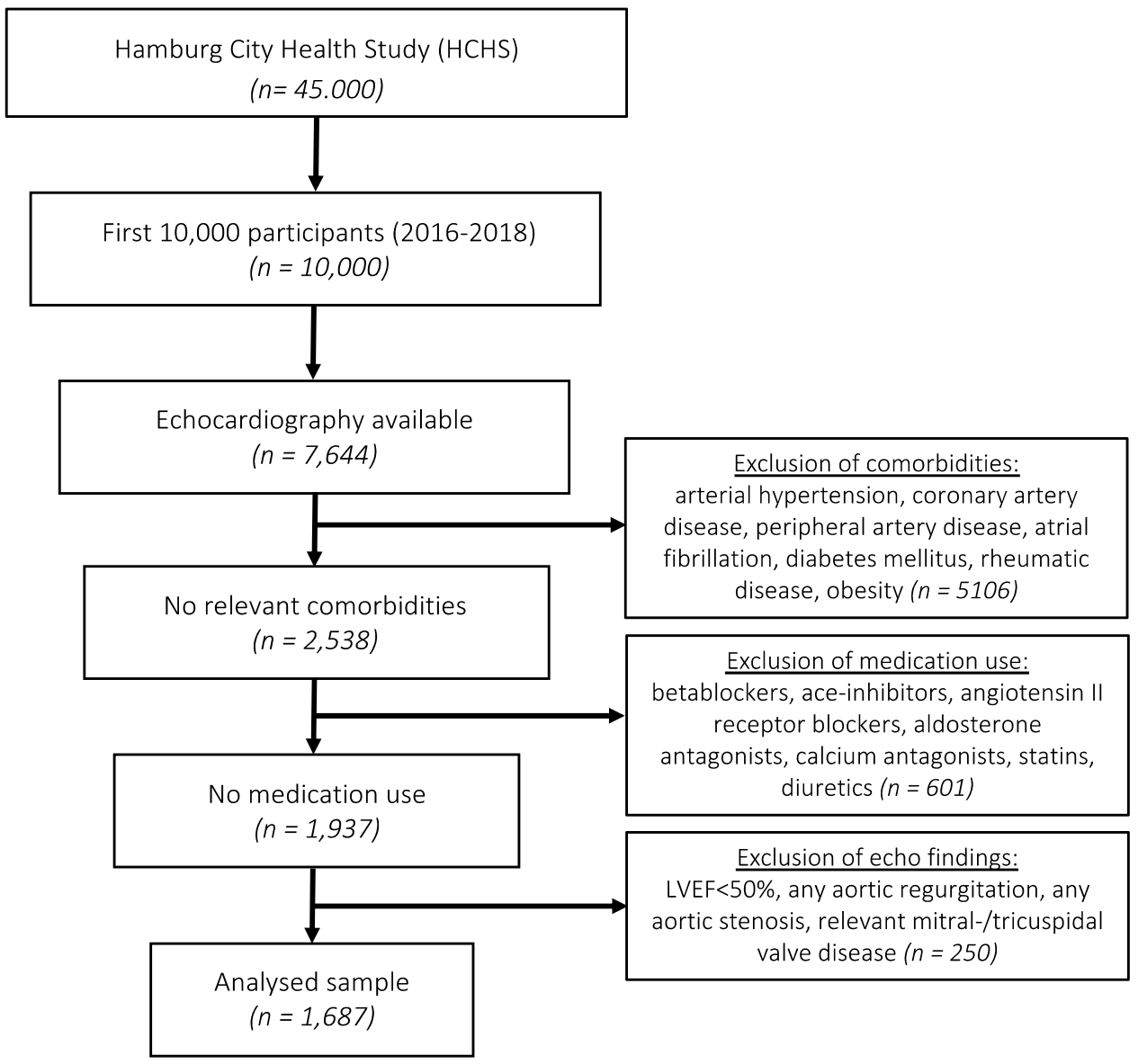

with the current guidelines of the American Society of Echocardiography (ASE) and the European Association of cardiovascular imaging (EACVI) [11, 12]. All TTE studies were independently quantified three times by three different investigators at a single reading centre, all blinded to the clinical information. For the assessment of intra-observer reproducibility, a set of 80 TTE studies was analysed twice by each investigator. The commercially available and established Siemens syngo SC2000 software was used (Siemens syngo SC 2000 Version 4.0, Siemens Healthineers, Erlangen, Germany) for echocardiography data analysis.
Systematic measurements of the aortic root were performed perpendicular to the proximal aortic axis in end-diastole (ED), (i.e., immediately before aortic valve opening) as well as in mid-systole (MS) including the following: (a) aortic annulus (AoAn), (b) sinus of Valsalva (SoV), (c) sinotubular junction (STJ), and (d) proximal ascending aorta (AscAo) at $2 \mathrm{~cm}$ range from the STJ as published before by our group [13]. AoAn was measured as the largest diameter between the hinge points of the non- and right coronary cusps of aortic valve, using the inner-edge to inner-edge (II) convention. According to the HCHS consensus, the $\mathrm{SoV}$ was measured using the
Fig. 2 Echocardiographic measurements of the aortic root in end-diastole (A) and midsystole (B). From left to right: (1) aortic annulus, (2) sinus of Valsalva, (3) sinotubular junction, and (4) proximal ascending aorta within $2 \mathrm{~cm}$ range of the STJ. The green arrows mark the measurement time points in relation to the ECG
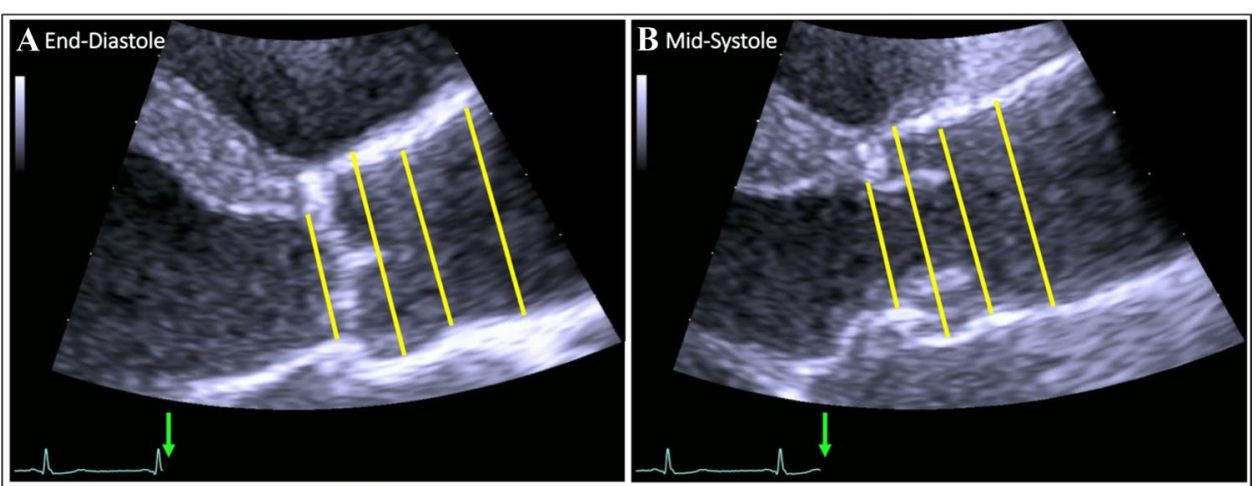
leading-edge to leading-edge (LL) convention, while II convention was used for the measurements of the STJ and AscAo (Fig. 2).

Left sided volumes and left ventricular ejection fraction were calculated using the two-dimensional biplane method of disks summation (modified Simpson's rule). In case of insufficient image quality for tracing the blood-tissue-border, no measurements were conducted. Left-sided diameters were measured in parasternal long-axis view (2-dimensional). Valvular heart disease was detected by a combination of visual assessment, colour Doppler, and continuous wave-Doppler following the current ASE and EACVI guidelines [14]. Aortic valve cuspidity was visually assessed in parasternal short- and long-axis view.

\section{Statistical analysis}

Magnitudes of continuous variables were presented as mean \pm standard deviation (SD) or median \pm interquartile range (IQR), accordingly. Intra-class correlation coefficient (ICC) estimates and their 95\% confident intervals (CI) were calculated based on a mean-rating, consistency, 2-way mixedeffects model [15].

The unpaired t-test was used to analyse differences between groups. For non-normally distributed variables, the Mann-Whitney U test was used instead. Pearson's correlation coefficient was used to quantify correlation between enddiastolic and mid-systolic measurements. For multiple group comparisons, overall significance levels were obtained using one-way anova. For multiple pairwise comparison against the base-mean, the t-test was used.

Multivariable linear regression was used to assess the association between aortic root diameters as dependent variables and either weight and height or BSA as independent variables. Weight, height, and BSA were not included in the same model to avoid multicollinearity. Age and sex were included as covariates in all regression models. Collinearity was controlled for by determining the variance inflation factor (VIF) for linear regression models. Inclusion of other baseline characteristics did not improve the model fit. Differences were considered statistically significant at a two-sided p-value level of 0.05 after post-hoc correction using the Bonferroni-Holm method. All statistical analyses were performed using $\mathrm{R}$ (version 4.0.3). A list of the used packages and versions can be found in the appendix.

\section{Results}

\section{Baseline characteristics}

A total of 1687 subjects (681 male and 1006 female) from the first 10,000 HCHS participants with a mean age of
Table 1 Characteristics of the study population

\begin{tabular}{|c|c|c|c|}
\hline & $\begin{array}{l}\text { Male } \\
(\mathrm{n}=681)\end{array}$ & $\begin{array}{l}\text { Female } \\
(n=1006)\end{array}$ & p-value \\
\hline \multicolumn{4}{|l|}{ Antrophometrics } \\
\hline Age & $58.3(8.0)$ & $57.9(7.4)$ & 0.310 \\
\hline Weight (kg) & $82.6(11.5)$ & $67.4(10.8)$ & $<0.001$ \\
\hline Height (cm) & $179.7(6.9)$ & $166.3(6.6)$ & $<0.001$ \\
\hline $\operatorname{BSA}\left(\mathrm{m}^{2}\right)$ & $2.0(0.2)$ & $1.7(0.1)$ & $<0.001$ \\
\hline BMI $\left(\mathrm{kg} / \mathrm{m}^{2}\right)$ & $25.5(3.0)$ & $24.4(3.6)$ & $<0.001$ \\
\hline Waist circumference, $\mathrm{cm}$ & $95.0(9.5)$ & $84.6(10.3)$ & $<0.001$ \\
\hline Heart rate, bpm & $65.9(10.6)$ & $68.9(8.9)$ & $<0.001$ \\
\hline Systolic bp (mmHg) & $128.4(9.5)$ & $123.7(11.2)$ & $<0.001$ \\
\hline Diastolic bp (mmHg) & $78.9(6.6)$ & $76.7(7.3)$ & $<0.001$ \\
\hline \multicolumn{4}{|l|}{ Laboratories } \\
\hline Hemoglobin, g/dl & $14.9(0.9)$ & $13.6(0.9)$ & $<0.001$ \\
\hline LDL (mg/dl) & $122.6(33.3)$ & $123.6(35.0)$ & 0.561 \\
\hline GFR (ml/min) & $87.5(11.7)$ & $87.0(12.7)$ & 0.454 \\
\hline NT-proBNP (ng/l) & $67.8(113.2)$ & $102.7(88.8)$ & $<0.001$ \\
\hline hsCRP, mg/l & $0.2(0.4)$ & $0.2(0.3)$ & 0.977 \\
\hline Fasting glucose (mg/dl) & $91.8(9.5)$ & $87.8(8.3)$ & $<0.001$ \\
\hline \multicolumn{4}{|l|}{ Echocardiographic data } \\
\hline LVEF (\%) & $58.6(4.0)$ & $60.2(4.5)$ & $<0.001$ \\
\hline $\operatorname{LVEDV~}\left(\mathrm{ml} / \mathrm{m}^{2}\right)$ & $130.9(29.6)$ & $103.7(23.2)$ & $<0.001$ \\
\hline LVESV (ml) & $54.2(13.2)$ & $41.2(10.8)$ & $<0.001$ \\
\hline LVEDD (mm) & $49.6(4.5)$ & $45.6(4.1)$ & $<0.001$ \\
\hline LV mass indexed $(\mathrm{g})$ & $85.8(17.2)$ & $73.6(13.9)$ & $<0.001$ \\
\hline $\mathrm{LAVI}, \mathrm{ml} / \mathrm{m}^{2}$ & $27.5(7.4)$ & $25.9(7.1)$ & $<0.001$ \\
\hline $\mathrm{E} / \mathrm{e}^{\prime}$ ratio & $6.6(1.5)$ & $7.2(1.8)$ & $<0.001$ \\
\hline TAPSE & $25.4(4.3)$ & $24.8(4.4)$ & 0.007 \\
\hline $\mathrm{TR} \mathrm{V}_{\max }$ & $2.3(0.2)$ & $2.3(0.2)$ & 0.409 \\
\hline
\end{tabular}

Continuous variables are presented as mean and standard deviation, and categorical variables are presented as absolute numbers and percentages

$B M I$ body mass index, $b p$ blood pressure, $B S A$ body surface area, $b p$ blood pressure, $L V E F$ left ventricular ejection fraction, $L V E D V$ left ventricular end-diastolic volume, $L V E S V$ left ventricular end-systolic volume, $L V E D D$ left ventricular end-diastolic diameter, $s d$ standard deviation

p-value for intergroup differences

$57.1 \pm 7.7$ (range 46-78) was included in the study. Per protocol, subjects were healthy adults with normal anthropometric and clinical characteristics (Table 1). Men showed higher BMI, weight, height, BSA, blood pressure, and left ventricular mass as well as larger left sided cavities as compared to the women. In contrast, women had higher LVEF.

\section{Feasibility and reliability of measurements}

AoAn MS and SoV ED showed the highest feasibility with approximately 97\%, while AscAo MS was assessable in only $51.5 \%$ of our cohort. There were no sex-specific differences 
in feasibility (Supplements, Table 6). Interobserver reproducibility values were high for all variables, as shown by ICC ranging from 0.95 to 0.99 . Intra-observer reproducibility was similar, with ICCs ranging between 0.90 and 0.99 .

\section{Aortic root reference values}

Absolute aortic root diameters were larger at all four measurement levels in men as compared to women, both in end-diastole and mid-systole. Indexing of aortic root diameters to BSA had a reverse effect and revealed significantly larger aortic root diameters for women (Table 2). Both non-indexed and indexed aortic root diameters increased significantly with increasing age in males and females (Supplement Table 5). Multiple linear regression analysis showed significant correlations between age, sex, BSA, weight, height, and aortic root diameter (Table 3). Integrating further variables, e.g. blood pressure (Supplement Table 7), waist circumference, left ventricular end-diastolic diameter, and left ventricular end-diastolic volume, did not relevantly improve the predictive capacity of our model. The strongest correlation in the multivariate model was found for the prediction of SoV diameters $\left(R^{2}=0.39\right.$ (BSA model); $\mathrm{R}^{2}=0.39$ (height model)). Age showed the weakest association with AoAn diameter in both models (i.e., $\beta=0.010 ; p \leq 0.001$ in the BSA model and $\beta=0.011$; $\mathrm{p} \leq 0.001$ in the height model). For visualization purpose, we prepared age-, sex-, height- and BSA-adjusted nomograms for all measured aortic root diameters (Figs. 3, 4, Supplements Fig. 6).

For all aortic root diameters, end-diastolic measurements correlated strongly with mid-systolic measurements in men and in women (AoAn: women: $R=0.63$, $\mathrm{p}<0.0001$, men: $\mathrm{R}=0.70, \mathrm{p}<0.0001$; SoV: women: $\mathrm{R}=0.91, \mathrm{p}<0.0001$, men: $\mathrm{R}=0.92, \mathrm{p}<0.0001 ; \mathrm{STJ}$ : women: $\mathrm{R}=0.87, \mathrm{p}<0.0001$, men: $\mathrm{R}=0.85, \mathrm{p}<0.0001$; AscAo: women: $\mathrm{R}=0.70, \mathrm{p}<0.0001$, men: $\mathrm{R}=0.76$, $\mathrm{p}<0.0001)$. The STJ/AoAn ratio increased significantly with an advancing age in men and in women, a finding which highlights a stronger age-dependency of STJ growth as compared to the AoAn (Fig. 5).

In line with this finding, our multiple linear regression analysis showed a stronger association between STJ diameter and age as compared to the correlation between age and AoAn diameter (Table 3). Based on our multiple linear regression analysis, formulas for the calculation of individual reference values of normal aortic root diameters were prepared which integrate age, sex, height, and weight (Table 4).

\section{Discussion}

The present study provides standardized echocardiographic aortic root reference values derived from the single-centre and population-based HCHS study based on state-of-the-art cardiac ultrasound.

Table 2 Echocardiographic measurements of the aortic root-absolute and indexed to BSA

\begin{tabular}{|c|c|c|c|c|c|c|}
\hline & \multicolumn{2}{|c|}{ Absolute diameters $(\mathrm{mm})$} & \multicolumn{4}{|c|}{ Diameters indexed to BSA $\left(\mathrm{mm} / \mathrm{m}^{2}\right)$} \\
\hline & $\begin{array}{l}\text { Male } \\
(\mathrm{n}=681)\end{array}$ & $\begin{array}{l}\text { Female } \\
(\mathrm{n}=1006)\end{array}$ & p-value & $\begin{array}{l}\text { Male } \\
(\mathrm{n}=681)\end{array}$ & $\begin{array}{l}\text { Female } \\
(n=1006)\end{array}$ & p-value \\
\hline ED aortic annulus & $\begin{array}{l}21.97 \\
{[21.86-22.08]}\end{array}$ & $\begin{array}{l}19.97 \\
{[19.89-20.05]}\end{array}$ & $<0.001$ & $\begin{array}{l}10.92 \\
{[10.84-10.99]}\end{array}$ & $\begin{array}{l}11.48 \\
{[11.42-11.55]}\end{array}$ & $<0.001$ \\
\hline ED sinus of valsalva & $\begin{array}{l}21.27 \\
{[21.15-21.39]}\end{array}$ & $\begin{array}{l}19.45 \\
{[19.37-19.54]}\end{array}$ & $<0.001$ & $\begin{array}{l}10.61 \\
{[10.53-10.68]}\end{array}$ & $11.19[11.12-11.26]$ & $<0.001$ \\
\hline ED sinotubular junction & $\begin{array}{l}35.96 \\
{[35.7-36.21]}\end{array}$ & $\begin{array}{l}31.83 \\
{[31.65-32.01]}\end{array}$ & $<0.001$ & $\begin{array}{l}17.88 \\
{[17.73-18.03]}\end{array}$ & $\begin{array}{l}18.28 \\
{[18.16-18.41]}\end{array}$ & $<0.001$ \\
\hline ED ascending aorta & $\begin{array}{l}27.91 \\
{[27.68-28.13]}\end{array}$ & $\begin{array}{l}25.15 \\
{[24.97-25.32]}\end{array}$ & $<0.001$ & $\begin{array}{l}13.88 \\
{[13.76-14.01]}\end{array}$ & $\begin{array}{l}14.42 \\
{[14.3-14.53]}\end{array}$ & $<0.001$ \\
\hline MS aortic annulus & $\begin{array}{l}30.95 \\
{[30.58-31.31]}\end{array}$ & $\begin{array}{l}28.31 \\
{[28.04-28.58]}\end{array}$ & $<0.001$ & $\begin{array}{l}15.37 \\
{[15.18-15.57]}\end{array}$ & $\begin{array}{l}16.19 \\
{[16.01-16.38]}\end{array}$ & $<0.001$ \\
\hline MS sinus of valsalva & $\begin{array}{l}31.05 \\
{[30.71-31.39]}\end{array}$ & $\begin{array}{l}28.17 \\
{[27.92-28.42]}\end{array}$ & $<0.001$ & $\begin{array}{l}15.42 \\
{[15.23-15.6]}\end{array}$ & $\begin{array}{l}16.12 \\
{[15.96-16.29]}\end{array}$ & $<0.001$ \\
\hline MS sinotubular junction & $\begin{array}{l}36.95 \\
{[36.67-37.24]}\end{array}$ & $\begin{array}{l}32.86 \\
{[32.66-33.05]}\end{array}$ & $<0.001$ & $\begin{array}{l}18.38 \\
{[18.22-18.54]}\end{array}$ & $\begin{array}{l}18.86 \\
{[18.72-19]}\end{array}$ & $<0.001$ \\
\hline MS ascending aorta & $\begin{array}{l}29.18 \\
{[28.89-29.46]}\end{array}$ & $\begin{array}{l}26.29 \\
{[26.09-26.48]}\end{array}$ & $<0.001$ & $\begin{array}{l}14.52 \\
{[14.37-14.68]}\end{array}$ & $\begin{array}{l}15.05 \\
{[14.93-15.18]}\end{array}$ & $<0.001$ \\
\hline
\end{tabular}

Continuous variables are presented as mean and $95 \%$ confidence interval. Abbreviations as in Table 1 p-value for intergroup differences 
Table 3 Multiple linear regression analyses of absolute aortic root diameters $(\mathrm{mm})$ measured in end-diastole with BSA or height/weight as independent variables adjusted for age and sex

\begin{tabular}{|c|c|c|c|c|c|c|}
\hline \multirow[t]{2}{*}{ End-diastolic diameters } & \multicolumn{3}{|c|}{ BSA model } & \multicolumn{3}{|c|}{ Height model } \\
\hline & $\mathrm{R}^{2}$ & $\beta$ & p-value & $\overline{\mathrm{R}^{2}}$ & $\beta$ & p-value \\
\hline Aortic annulus & 0.35 & & & 0.36 & & \\
\hline Age & & 0.010 & 0.730 & & 0.011 & 0.526 \\
\hline Male sex & & 1.088 & $<0.001$ & & 1.075 & $<0.001$ \\
\hline BSA & & 2.717 & $<0.001$ & & & \\
\hline Height & & & & & 0.025 & 0.002 \\
\hline Weight & & & & & 0.027 & $<0.001$ \\
\hline Sinus of valsalva & 0.39 & & & 0.39 & & \\
\hline Age & & 0.099 & $<0.001$ & & 0.106 & $<0.001$ \\
\hline Male sex & & 2.390 & $<0.001$ & & 2.160 & $<0.001$ \\
\hline BSA & & 6.327 & $<0.001$ & & & \\
\hline Height & & & & & 0.087 & $<0.001$ \\
\hline Weight & & & & & 0.051 & $<0.001$ \\
\hline Sinotubular junction & 0.30 & & & 0.30 & & \\
\hline Age & & 0.072 & $<0.001$ & & 0.079 & $<0.001$ \\
\hline Male sex & & 1.335 & $<0.001$ & & 1.103 & $<0.001$ \\
\hline BSA & & 5.358 & $<0.001$ & & & \\
\hline Height & & & & & 0.080 & $<0.001$ \\
\hline Weight & & & & & 0.040 & $<0.001$ \\
\hline Ascending aorta & 0.19 & & & 0.19 & & \\
\hline Age & & 0.072 & $<0.001$ & & 0.071 & $<0.001$ \\
\hline Male sex & & 1.215 & 0.002 & & 1.308 & 0.002 \\
\hline BSA & & 5.467 & $<0.001$ & & & \\
\hline Height & & & & & 0.031 & $<0.001$ \\
\hline Weight & & & & & 0.064 & $<0.001$ \\
\hline
\end{tabular}

$B S A$ body surface area

\section{Impact of the methodological approach}

Most of the published echocardiographic studies on aortic root dimensions used primarily M-mode technique providing high spatial resolution at the cost of angle dependency [6, 7]. Nevertheless, M-mode echocardiography was superseded and replaced by 2D-technique. In our current study we used a novel approach to define specific aortic root diameters in 2D-echocardiography using a combination of two measuring modalities: the LL and II convention. While the LL convention is the most used measuring technique for echocardiography in adults, other imaging modalities (i.e., CMR and CT) utilize predominantly the II convention. In recent ASE/EACVI guidelines, the consensus has been obtained to continue using the LL convention for echocardiography due to reduced artefacts with LL measurements and insufficient validation of the II method [11, 12]. Nevertheless, the LL convention has important limitations: For AoAn measurements, the detection of the leading edge is severely limited by aortic valve degeneration, especially in the setting of valvular calcification. Therefore, the ASE/EACVI recommends measuring the AoAn using the II convention. The STJ has a much thinner wall and more extensive movement amplitude during the cardiac cycle as compared to the SoV, which complicates the definition of the anterior leading edge and, therefore, the II measurement method might be advantageous. Furthermore, previous data indicate that the LL convention tends to overestimate aortic diameters as compared to CT measurements which predominantly use the II convention [16]. Therefore, the interdisciplinary consensus in the HCHS study was to measure AoAn, STJ, and AscAo diameters using the II convention, while SoV diameters were defined using the LL convention.

Another important feature of our echocardiographic analysis is the systematic measurement of all aortic root diameters in systole and diastole. Until now, there is no consensus regarding the value and the clinical impact of mid-systolic (MS) vs. end-diastolic (ED) aortic root measurements. In recent years, the trend has been towards end-diastolic aortic root measurements [11]. Yet, enddiastolic measurements are occasionally imprecise due to limited echocardiographic image quality. In particular, the insertion of the right coronary and non-coronary cusps is much better visible at mid-systole and facilitates reliable measurements. Given the fact that mid-systolic aortic root measurements correlate better with intraoperative 

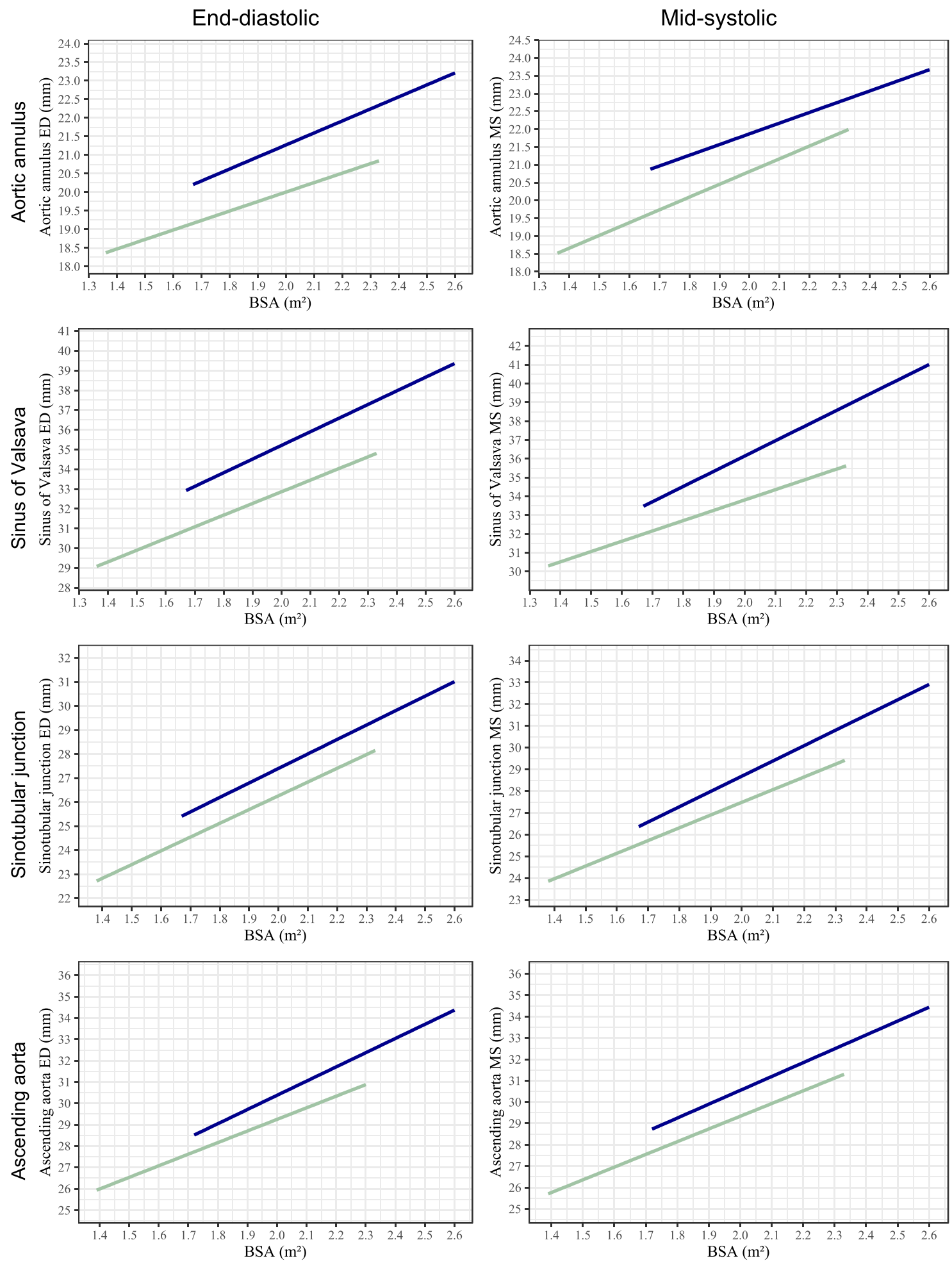

Female - Male

Fig. 3 Nomograms of aortic root diameters for women and men $\leq 60$ years at end-diastole and mid-systole in relation to body surface area. $\mathrm{X}$-axis represents body surface area in square meters, $\mathrm{y}$-axis represents aortic root diameters in millimeters. BSA body surface area 

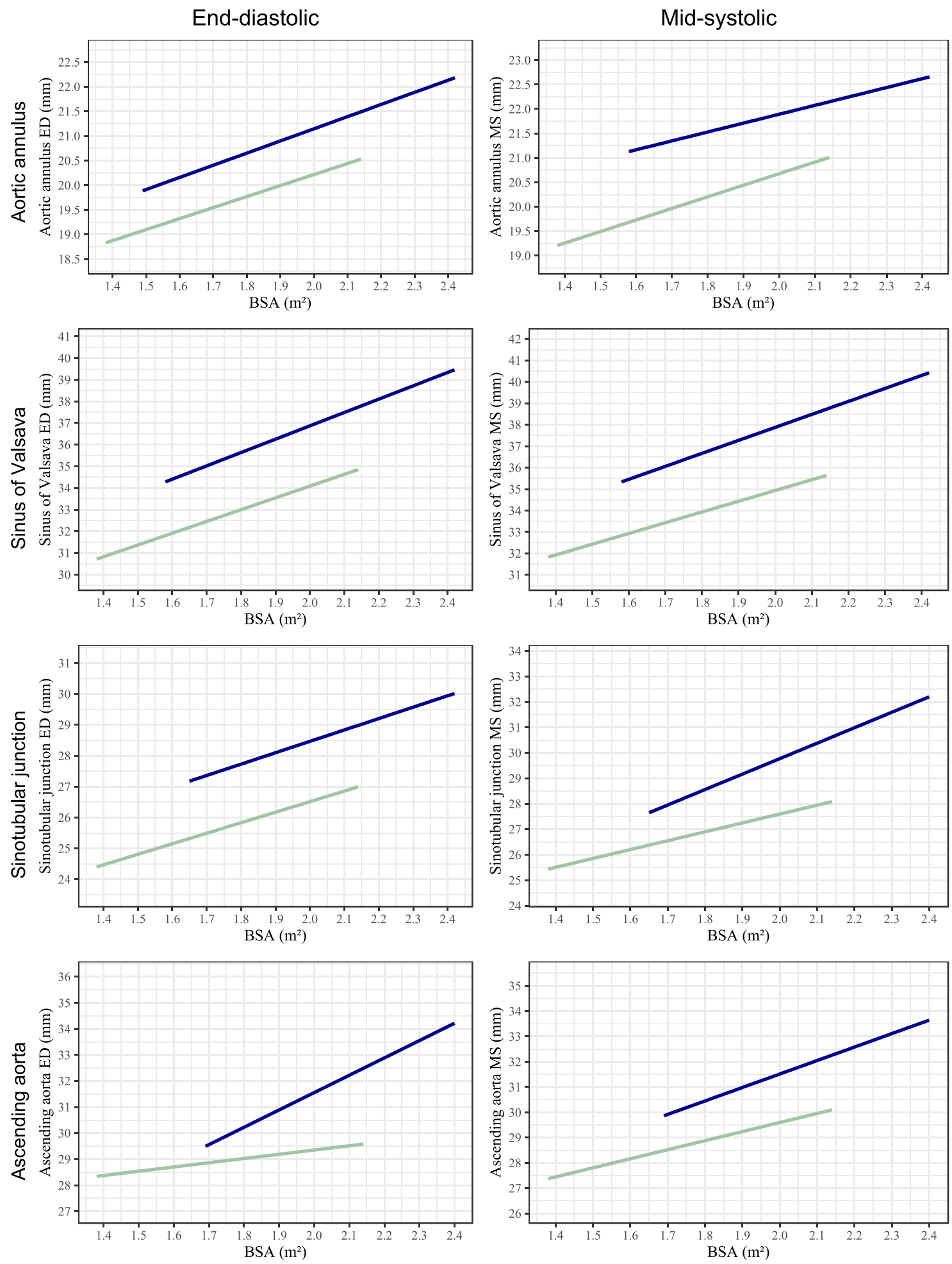

Female Male

Fig. 4 Nomograms of aortic root diameters for women and men $>60$ years at end-diastole and mid-systole in relation to BSA. X-axis represents BSA in square meters, $y$-axis represents aortic root diameters in millimeters. BSA body surface area 
Fig. 5 Ratio of sinotubular junction and aortic annulus plotted against age categories stratified by sex. P value for overall difference between age groups. Significance levels for pairwise comparison against the age group 45-49. $\mathrm{ns}=\mathrm{p}>0.05$, $* \mathrm{p} \leq 0.05, * * \mathrm{p} \leq 0.01$, $* * * \mathrm{p} \leq 0.001, * * * * \mathrm{p} \leq 0.0001$ $A o A n$ aortic annulus, $E D$ enddiastolic, $M S$ mid-systolic, STJ sinotubular junction

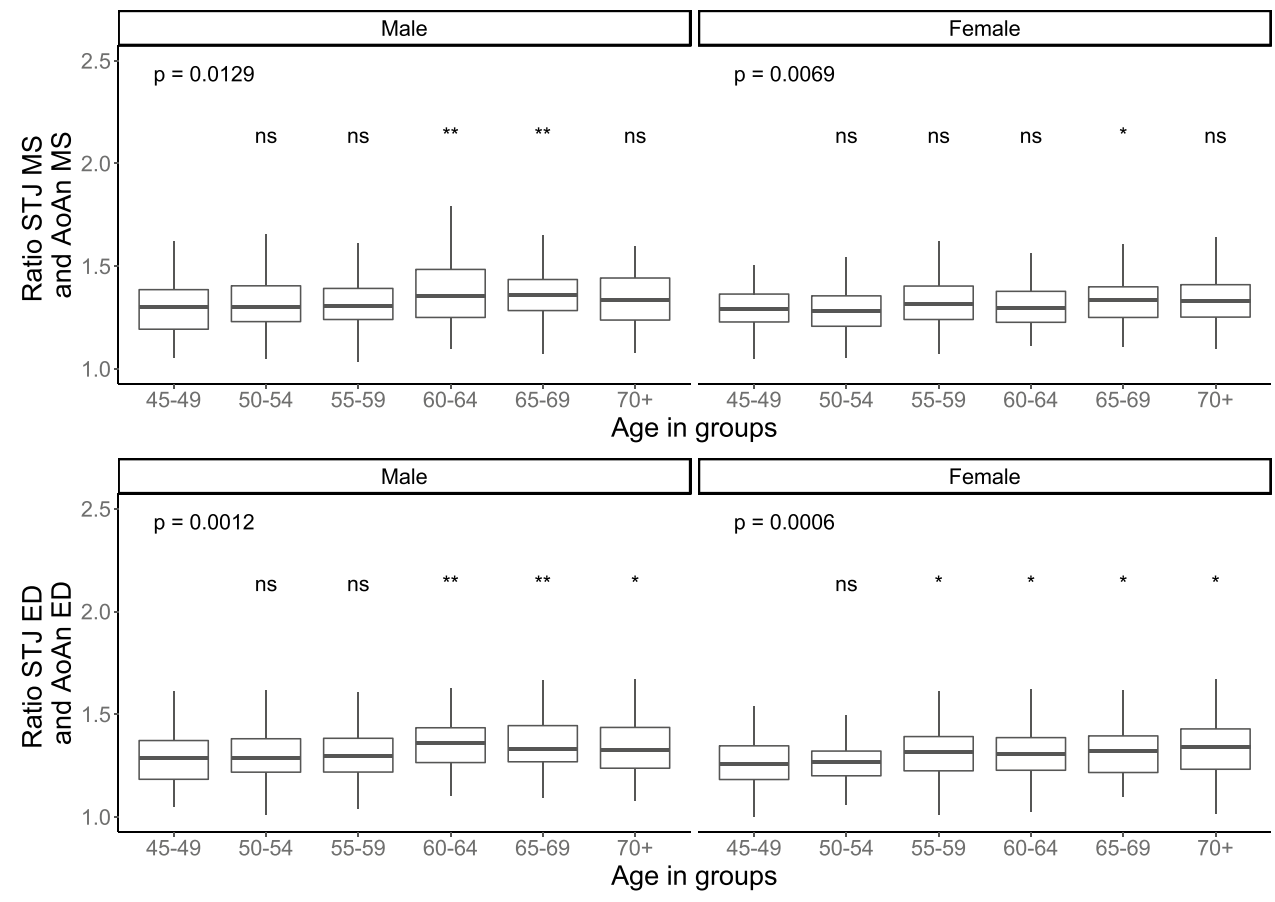

Table 4 Formulas for specific calculation of individual end-diastolic, absolute aortic root reference values derived from multiple linear regression analyses

\begin{tabular}{|c|c|c|}
\hline \multicolumn{2}{|l|}{ Aortic measurement } & \multirow{2}{*}{$\begin{array}{l}\text { Formula for calculation of normal aortic root diameter } \\
\text { AoAn }=10.828+\text { Age }(\text { years }) * 0.001+0 \text { (Females) } \mid 1 \text { (Males) } * 0.871 \\
+ \text { Height }(\mathrm{cm}) * 0.013+\text { Weight }(\mathrm{kg}) * 0.020\end{array}$} \\
\hline Aortic annulus & Lower & \\
\hline & Higher & $\begin{array}{l}\text { AoAn }=14.970+\text { Age }(\text { years }) * 0.020+0 \text { (Females) } \mid 1 \text { (Males) } * 1.278 \\
+ \text { Height }(\mathrm{cm}) * 0.037+\text { Weight }(\mathrm{kg}) * 0.034\end{array}$ \\
\hline \multirow[t]{2}{*}{ Sinus of Valsalva } & Lower & $\begin{aligned} & \text { SoV }=3.483+\text { Age }(\text { years }) * 0.086+0 \text { (Females) } \mid 1 \text { (Males) } * 1.731 \\
&+ \text { Height }(\mathrm{cm}) * 0.062+\text { Weight }(\mathrm{kg}) * 0.036\end{aligned}$ \\
\hline & Higher & $\begin{array}{l}\text { SoV }=12.129+\text { Age }(\text { years }) * 0.125+0 \text { (Females) } \mid 1 \text { (Males) } * 2.589 \\
+ \text { Height }(\mathrm{cm}) * 0.113+\text { Weight }(\mathrm{kg}) * 0.065\end{array}$ \\
\hline \multirow[t]{2}{*}{ Sinotubular junction } & Lower & $\begin{array}{l}\text { STJ }=0.600+\text { Age }(\text { years }) * 0.061+0 \text { (Females) } \mid 1 \text { (Males) } * 0.707 \\
+ \text { Height }(\mathrm{cm}) * 0.056+\text { Weight }(\mathrm{kg}) * 0.026\end{array}$ \\
\hline & Higher & $\begin{aligned} & \mathrm{STJ}=8.562+\text { Age }(\text { years }) * 0.097+0 \text { (Females) } \mid 1 \text { (Males) } * 1.499 \\
&+ \text { Height }(\mathrm{cm}) * 0.103+\text { Weight }(\mathrm{kg}) * 0.054\end{aligned}$ \\
\hline \multirow[t]{2}{*}{ Ascending aorta } & Lower & $\begin{array}{l}\text { AscAo }=8.189+\text { Age (years) } * 0.041+0 \text { (Females) I } 1 \text { (Males) } * 0.655 \\
+ \text { Height }(\mathrm{cm}) *-0.007+\text { Weight }(\mathrm{kg}) * 0.040\end{array}$ \\
\hline & Higher & $\begin{array}{l}\text { AscAo }=21.214+\text { Age }(\text { years }) * 0.101+0 \text { (Females) } \mid 1 \text { (Males) } * 1.961 \\
+ \text { Height }(\mathrm{cm}) * 0.069+\text { Weight }(\mathrm{kg}) * 0.087\end{array}$ \\
\hline
\end{tabular}

Models integrate age, sex, height, and weight. Imputation of values of a specific person leads to prediction of aortic root diameters measurements in the paediatric population, the 2010 ASE paediatric guidelines recommend aortic root measurements at mid-systole [17]. However, there are still several strong arguments to insist on end-diastolic aortic root measurements. First of all, end-diastolic aortic root measurements have a clear advantage of the well-defined timepoint of measurement (i.e., ECG-triggered at the onset of the QRS complex) and the beneficial hemodynamic condition of stable aortic pressure. Furthermore, aortic valve competence is primarily maintained by diastolic AoAn and STJ shape. Therefore, the definition of end-diastolic aortic root diameters may be more relevant for clinical decisions, while trying to answer the question of the optimal AoAn diameter that is required to restore aortic valve. Due to these considerations, end-diastole has been recommended as the timepoint for echocardiographic aortic root measurement in adults by the ASE/EACVI [12]. Given this controversy, we decided to perform both end-diastolic and mid-systolic aortic root measurements in our current study. 


\section{Rationale for matching of aortic root diameters}

The variation of aortic root diameters found in the population-based HCHS study correlates well with the so far published studies of similar design [6-8, 18-25]. Previous studies revealed a marked heterogeneity of aortic root diameters that varied significantly depending on sex, age, and BSA.

Aortic root diameters were strongly related to male sex $(+2.7 \mathrm{~mm}$ adjusted for BSA and age) in a study published by Devereux et al. [8]. The Framingham Heart Study showed on average $2.4 \mathrm{~mm}$ smaller aortic root dimensions in women than that of men of comparable age and BSA [7]. Similar sex effects have been demonstrated in a smaller Japanese population which revealed $3 \mathrm{~mm}$ larger absolute aortic root diameters in men vs. women [19]. A reverse trend after indexing the STJ and AscAo diameters for BSA has been reported in athletes and the general population [18, 25]. Similarly, we found significantly larger indexed aortic root diameters in women at all measured aortic root levels.

Previous echocardiographic studies revealed a constant association between aortic root diameters and age [18, 19, 24, 26]. All these studies described an increase of aortic root size by $0.7-1.0 \mathrm{~mm} /$ decade in different populations. In the present study, we calculated the growth of aortic root diameters separately at all measured levels and found that AoAn grows slower $(0.10 \mathrm{~mm} / \mathrm{dec}$ ade $)$ compared to the SoV (1.0 mm/decade), STJ (0.79 mm/decade), and AoAsc (0.71 mm/decade).

Strong correlation has been consistently reported between aortic root diameters and height, weight, and BSA in the normal adult population $[7,8,18,19,24]$. In line with previous studies, to these findings, we found no relevant difference between including height and weight vs. BSA alone in our multivariate linear regression model [8, 18]. Moreover, integrating more biological and clinical data did not improve the prediction of aortic root diameters. Hence, we created formulas for the calculation of individualized end-diastolic aortic root reference values that integrate age, sex, height, and weight as simple and readily available variables (Table 4). However, some limitations of such linear models should be considered. In particular, they are able to provide only limited information regarding the individual aortic root diameters, as they cover maximally $39 \%$ of the absolute variance (i.e., adjusted R-values from 0.19 to 0.39 ). This limitation should be considered in the clinical practice when defining "normal" aortic root diameters in individual patients.

\section{Limitations}

Our study sample, which represents a sample of the first 10.000 subjects of the HCHS, originates from an at random selected population of the city of Hamburg. Although being a variegated, multicultural city, most subjects are of
Caucasian ascend. Due to the exclusion of all subjects with relevant comorbidities, females were overrepresented in our sample. Furthermore, subjects included in HCHS were between 45 to 78 years old resulting in no representation of subjects at younger age. Therefore, the applicability of our findings in different populations should be done cautiously. Lastly, we combined the II and LL conventions in aortic root measurements which is not a validated approach. Further correlation studies comparing echocardiographic measurements with other imaging modalities (i.e., CMR, CT) are needed to establish a standardized and uniform measuring method.

\section{Conclusion}

The present study provides reference values of aortic root diameters based on a standardized and validated echocardiographic protocol in a large, at random-selected populationbased study. Furthermore, we defined age-, sex-, and BSAadjusted aortic root diameters stratified by the time of heart cycle to support clinical decision-making algorithms in the monitoring and treatment of aortic valve and root disease.

Supplementary Information The online version contains supplementary material available at https://doi.org/10.1007/s10554-021-02354-5.

Acknowledgements The authors acknowledge the participants of the Hamburg City Health Study, the staff at the Epidemiological Study Centre, cooperation partners, patrons and the Deanery from the University Medical Centre Hamburg. In particular, the authors acknowledge Professor Stefan Blankenberg for his great effort not only in initiating the Hamburg City Health Study but also for his tireless scientific supervision.

Author contribution The authors do hereby declare that all illustrations and figures in the manuscript are entirely original and do not require reprint permission.

Funding Open Access funding enabled and organized by Projekt DEAL. The HCHS is supported by the Innovative medicine initiative [Grant Number 116074], by the Foundation Leducq [grant number 16 CVD 03], by the euCanSHare grant agreement [grant number 825903-euCanSHare H2020], and the Deutsche Forschungsgemeinschaft [Grant Number TH1106/5-1; AA93/2-1]. Furthermore, it is supported by the participating institutes and departments from the University Medical Centre Hamburg-Eppendorf, which contribute with individual and scaled budgets to the overall funding. Technical equipment is provided by SIEMENS according to a contract for 12 years, the Schiller AG on a loan basis for six years, and Topcon on a loan basis from 2017 until 2022. The Hamburg City Health Study is additionally supported by an unrestricted Grant (2017 to 2022) by Bayer. Project-related analyses are supported by Amgen, Astra Zeneca, BASF, Deutsche Gesetzliche Unfallversicherung (DGUV), Deutsches Krebsforschungszentrum (DKFZ), Deutsches Zentrum für Herz-KreislaufForschung (DZHK), Deutsche Stiftung für Herzforschung, Novartis, Seefried Stiftung, and Unilever. The study is further supported by donations from the "Förderverein zur Förderung der HCHS e.V.", TePe ${ }^{\circledR}$ (2014) and Boston Scientific (2016). A current list of the supporters is 
online available on www.uke.de/hchs. Sponsor funding has in no way influenced the content or management of this study.

Data availability The data underlying this article cannot be shared publicly due to the privacy of individuals that participated in the study. The data will be shared on reasonable request to the corresponding author.

Code availability Will be shared on reasonable request.

\section{Declarations}

Conflict of interest EG reports honoraria from Edwards, Medtronic, LivaNova, and Aesculap, outside of the submitted work. SB reports honoraria from Abbott, Siemens, Thermo Fisher, and Roche, outside of the submitted work.

Ethical approval The authors do hereby declare that their study complies with the Declaration of Helsinki.

Open Access This article is licensed under a Creative Commons Attribution 4.0 International License, which permits use, sharing, adaptation, distribution and reproduction in any medium or format, as long as you give appropriate credit to the original author(s) and the source, provide a link to the Creative Commons licence, and indicate if changes were made. The images or other third party material in this article are included in the article's Creative Commons licence, unless indicated otherwise in a credit line to the material. If material is not included in the article's Creative Commons licence and your intended use is not permitted by statutory regulation or exceeds the permitted use, you will need to obtain permission directly from the copyright holder. To view a copy of this licence, visit http://creativecommons.org/licenses/by/4.0/.

\section{References}

1. Reid CL, Anton-Culver H, Yunis C, Gardin JM (2007) Prevalence and clinical correlates of isolated mitral, isolated aortic regurgitation, and both in adults aged 21 to 35 years (from the CARDIA study). Am J Cardiol 99(6):830-834

2. Seder JD, Burke JF, Pauletto FJ (1990) Prevalence of aortic regurgitation by color flow Doppler in relation to aortic root size. J Am Soc Echocardiogr 3(4):316-319

3. Lai CL, Chien KL, Hsu HC, Su TC, Chen MF, Lee YT (2010) Aortic root dimension as an independent predictor for all-cause death in adults $<65$ years of age (from the chin-shan community cardiovascular cohort study). Echocardiography 27(5):487-495

4. Guiney TE, Davies MJ, Parker DJ, Leech GJ, Leatham A (1987) The aetiology and course of isolated severe aortic regurgitation: A clinical, pathological, and echocardiographic study. Heart 58(4):358-368

5. Gardin JM, Arnold AM, Polak J, Jackson S, Smith V, Gottdiener $\mathrm{J}$ (2006) Usefulness of aortic root dimension in persons $\geq 65$ years of age in predicting heart failure, stroke, cardiovascular mortality, all-cause mortality and acute myocardial infarction (from the Cardiovascular Health Study). Am J Cardiol 97(2):270-275

6. Roman MJ, Devereux RB, Kramer-Fox R, O'Loughlin J (1989) Two-dimensional echocardiographic aortic root dimensions in normal children and adults. Am J Cardiol 64(8):507-512

7. Vasan RS, Larson MG, Benjamin EJ, Levy D (1995) Echocardiographic reference values for aortic root size: The Framingham Heart Study. J Am Soc Echocardiogr 8(6):793-800
8. Devereux RB, De Simone G, Arnett DK, Best LG, Boerwinkle E, Howard BV et al (2012) Normal limits in relation to age, body size and gender of two-dimensional echocardiographic aortic root dimensions in persons $>15$ years of age. Am J Cardiol 110(8):1189-1194. https://doi.org/10.1016/j.amjcard.2012.05.063

9. Savage DD, Garrison RJ, Kannel WB, Anderson SJ, Feinleib M, Castelli WP (1987) Considerations in the use of echocardiography in epidemiology. The Framingham Study. Hypertension 9(2):40-44

10. Jagodzinski A, Johansen C, Koch-Gromus U, Aarabi G, Adam G, Anders S et al (2020) Rationale and design of the Hamburg City Health Study. Eur J Epidemiol 35(2):169-181

11. Goldstein SA, Evangelista A, Abbara S, Arai A, Asch FM, Badano LP et al (2015) Multimodality imaging of diseases of the thoracic aorta in adults: from the American Society of Echocardiography and the European Association of Cardiovascular Imaging. J Am Soc Echocardiogr 28(2):119-182

12. Lang RM, Badano LP, Mor-Avi V, Afilalo J, Armstrong A, Ernande L et al (2015) Recommendations for cardiac chamber quantification by echocardiography in adults: an update from the American society of echocardiography and the European association of cardiovascular imaging. J Am Soc Echocardiogr 16(3):233-271. https://doi.org/10.1016/j.echo.2014.10.003

13. Wenzel JP, Petersen E, Nikorowitsch J, Müller J, Kölbel T (2021) Aortic root dimensions as a correlate for aortic regurgitation' s severity. Int J Cardiovasc Imaging. https://doi.org/10. 1007/s10554-021-02337-6

14. Eacts CS, Germany CH, Rosenhek R, France EL, Rodriguez D, Tornos P et al (2017) 2017 ESC/EACTS Guidelines for the management of valvular heart disease The Task Force for the Management of Valvular Heart Disease of the European Society of Cardiology (ESC) and the European. Eur Heart J 38:2739-2786

15. Shrout PE, Fleiss JL (1979) Intraclass correlations: uses in assessing rater reliability. Psychol Bull 86(2):420-428

16. Lin FY, Devereux RB, Roman MJ, Meng J, Jow VM, Jacobs A et al (2008) Assessment of the thoracic aorta by multidetector computed tomography: age- and sex-specific reference values in adults without evident cardiovascular disease. J Cardiovasc Comput Tomogr 2(5):298-308

17. Lopez L, Colan SD, Frommelt PC, Ensing GJ, Kendall K, Younoszai AK et al (2010) Recommendations for Quantification Methods During the Performance of a Pediatric Echocardiogram: A Report From the Pediatric Measurements Writing Group of the American Society of Echocardiography Pediatric and Congenital Heart Disease Council. J Am Soc Echocardiogr 23(5):465-495

18. Saura D, Dulgheru R, Caballero L, Bernard A, Kou S, Gonjilashvili N et al (2017) Two-dimensional transthoracic echocardiographic normal reference ranges for proximal aorta dimensions: results from the EACVI NORRE study. Eur Heart J Cardiovasc Imaging 18(2):167-179

19. Daimon M, Watanabe H, Abe Y, Hirata K, Hozumi T, Ishii K et al (2008) Normal values of echocardiographic parameters in relation - the JAMP study. Circ J 72:1859-1866

20. Mirea O, Maffessanti F, Gripari P, Tamborini G, Muratori M, Fusini L et al (2013) Effects of aging and body size on proximal and ascending aorta and aortic arch: inner edge-to-inner edge reference values in a large adult population by two-dimensional transthoracic echocardiography. J Am Soc Echocardiogr 26(4):419-427

21. Son MK, Chang SA, Kwak JH, Lim HJ, Park SJ, Choi JO et al (2013) Comparative measurement of aortic root by transthoracic echocardiography in normal Korean population based on two different guidelines. Cardiovasc Ultrasound 11(1):1-8

22. Muraru D, Maffessanti F, Kocabay G, Peluso D, Bianco LD, Piasentini E et al (2014) Ascending aorta diameters measured by 
echocardiography using both leading edge-to-leading edge and inner edge-to-inner edge conventions in healthy volunteers. Eur Heart J Cardiovasc Imaging 15(4):415-422

23. Fitzgerald BT, Kwon A, Scalia GM (2015) The new dimension in aortic measurements - use of the inner edge measurement for the thoracic aorta in australian patients. Hear Lung Circ 24(11):1104 1110. https://doi.org/10.1016/j.hlc.2015.05.001

24. Vriz O, Aboyans V, D’Andrea A, Ferrara F, Acri E, Limongelli G et al (2014) Normal values of aortic root dimensions in healthy adults. Am J Cardiol 114(6):921-927. https://doi.org/10.1016/j. amjcard.2014.06.028

25. Boraita A, Heras M-E, Morales F, Marina-Breysse M, Canda A, Rabadan M et al (2016) Reference values of aortic root in male and female white elite athletes according to sport. Circ Cardiovasc Imaging 9:10

26. Vasan RS, Larson MG, Levy D (1995) Determinants of echocardiographic aortic root size. The Framingham Heart Study. Circulation 91(3): 734-740

Publisher's Note Springer Nature remains neutral with regard to jurisdictional claims in published maps and institutional affiliations. 